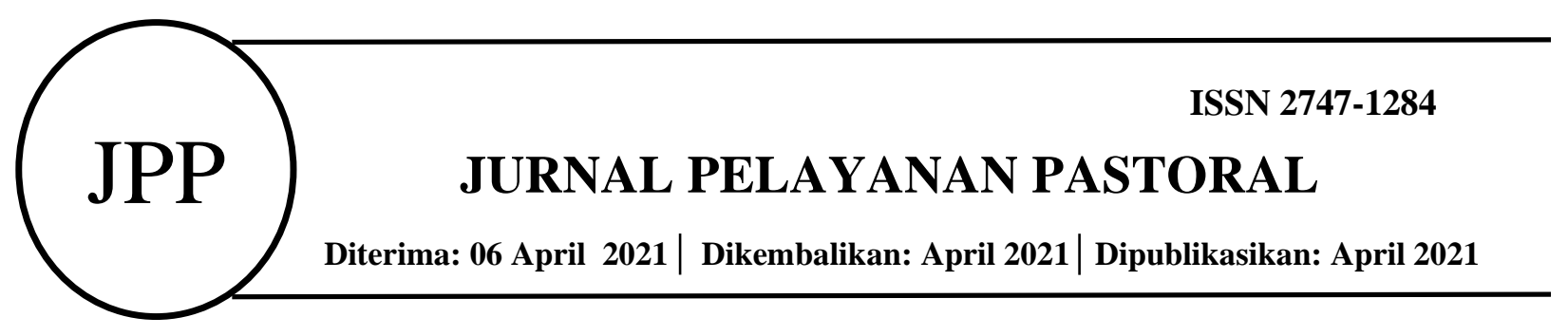

\title{
SURVEY HASIL PELAKSANAAN KATEKESE UMAT TENTANG LITERASI EKOLOGIS BAGI PENYANDANG DISABILITAS DI WISMA BHAKTI LUHUR MONDOROKO MALANG
}

\author{
Sri Wahyuni*1, Yovita Kui*2 \\ ${ }^{1}$ Dosen Prodi Pelayanan Pastoral, ${ }^{2}$ Mahasiswa Prodi Pelayanan Pastoral STP-IPI Malang \\ email: ${ }^{1}$ sriwahyuni19370@gmail.com, 2maria.yovitakui1995@gmail.com
}

\begin{abstract}
Abstrak
Pemberian pemahaman tentang literasi ekologi tidak hanya diberikan kepada orang khalayak (normal) tetapi juga harus diberikan kepada para penyandang disabilitas. Tujuan dari penelitian ini adalah untuk memperoleh gambaran tentang pelaksanaan katekese umat tentang literasi ekologi bagi penyandang disabilitas di lingkungan santo Filemon Mondoroko Malang. Subjek penelitian adalah para penyandang disabilitas yang berada di asrama Mondoroko di wilayah lingkungan santo Filemon. Teknik pengambilan data dengan angket/kuesioner Instrumen yang dipakai terkait metode kuesioner ini ialah angket dengan skala Gutman dengan jawaban tegas ya atau tidak. Sampel yang dipakai ialah sample random sampling Jenis penelitiannya ialah penelitian kuantitatif. Desain penelitiannya ialah penelitian survei. Jumlah populasinya 42 penyandang disabilitas yang ada di wisma Bhakti Luhur Mondoroko. sedangkan sampelnya berjumlah 10 penyandang disabilitas tunagrahita. Dari hasil penelitian survei aksi nyata pelaksanaan katekese umat tentang literasi ekologi bagi para penyandang disabilitas tunagrahita ternyata hasilnya cukup signifikan yaitu dari 10 penyandang tunagrahita yang dipantau diperoleh hasil 93,9\%. Ini menunjukkan bahwa mereka sangat antusias untuk ikut ambil bagian dalam pemeliharaan lingkungan. Tetapi perlu juga diingat bahwa karena mereka penyandang disabilitas maka aksi nyata mereka perlu terus dipantau.
\end{abstract}

Kata kunci: Katekese Umat, Literasi Ekologi, Penyandang Disabilitas

\begin{abstract}
Providing an understanding of ecological literacy should not only be given to the general public (normal) but must also be given to persons with disabilities The purpose of this study was to obtain an overview of the implementation of catechesis by people regarding ecological literacy for persons with disabilities in the saint Filemon Mondoroko Malang. The research subjects were persons with disabilities residing in the Mondoroko hostel in the area of Saint Filemon. The data collection technique was using a questionnaire. The instrument used for this questionnaire method was a Gutman scale questionnaire with a firm answer, yes or no. The sample used is random sample sampling. This type of research is quantitative research. The research design is survey research. The total population is 42 persons with disabilities in the Bhakti Luhur Mondoroko guesthouse, while the sample is 10 persons with mental retardation disabilities. From the results of the real action survey research on the implementation of catechesis of the people on ecological literacy for people with mental retardation, the results were quite significant, namely that out of 10 people with mental retardation who were monitored, the results were 93.9\%. This shows that they are very enthusiastic about taking part in environmental care. But it should also be remembered that because they are persons with disabilities, their real actions need to be continuously monitored.
\end{abstract}

Keywords: Catechesis of the People, Ecological Literacy, Persons with Disabilities 


\section{PENDAHULUAN}

Pelestarian lingkungan hidup menjadi salah satu perhatian dunia saat ini, hal ini dikarenakan sumber daya alam dan lingkungan sudah mulai menipis dan rusak akibat sikap dan perilaku tidak peduli manusia. Banyak permasalahan yang muncul karena lingkungan krisis seperti pemanasan global, meluasnya gurun, krisis keragaman hayati gangguan pada lapisan ozon dan hutan hujan tropis serta polusi air dan polusi udara semakin meningkat. Hal ini mendorong adanya upaya untuk melakukan perbaikan dan pelestarian lingkungan hidup.

Kemampuan yang dimiliki setiap individu untuk berperilaku baik dalam kesehariannya dengan menggunakan pemahamannya terhadap kondisi lingkungan itulah yang disebut dengan literasi lingkungan atau environment literacy (Salome, 2011). Pengetahuan dan kesadaran tentang keberadaan dan ruang lingkup masalah lingkungan adalah penting karena dapat membangkitkan kepedulian dan perhatian terhadap lingkungan. Menurut McBeth (2010) kemampuan literasi lingkungan seseorang dapat diukur melalui empat komponen yaitu: (1). Pengetahuan lingkungan yang meliputi dasar-dasar lingkungan; (2). Sikap terhadap lingkungan yang meliputi pandangan tentang lingkungan, kepekaan terhadap kondisi lingkungan, dan perasaan terhadap lingkungan; (3) ketrampilan kognitif yang meliputi identifikasi masalah lingkungan, analisis lingkungan dan pelaksanaan perencanaan; dan (4) perilaku yang meliputi tindakan nyata terhadap lingkungan.

Komponen-komponen tersebut merupakan acuan yang digunakan untuk menilai sejauh mana pemahaman literasi lingkungan seseorang. Cukup banyak strategi yang telah ditempuh untuk memperbaiki kualitas lingkungan, mulai dari penyuluhan, penataran, bimbingan, proyek percontohan dan perbaikan komponen yang menyebabkan rusaknya lingkungan seperti reboisasi, kali bersih, Jumat bersih dan gerakan sadar kebersihan serta program-program lainnya yang dapat menumbuhkan literasi lingkungan dalam kehidupan masyarakat. Semua teknik yang disebutkan di atas biasanya dilaksanakan oleh para pemerhati lingkungan baik dari pihak Pemerintah lewat Dinas Lingkungan Hidup (DLH) maupun swasta misalnya adalah Wahana Lingkungan Hidup Indonesia (WALHI).untuk memberikan edukasi betapa pentingnya menjaga kelestarian lingkungan hidup.

Memberikan edukasi betapa pentingnya menjaga lingkungan hidup tentunya diberikan kepada siapa saja tanpa terkecuali termasuk kepada para penyandang disabilitas. Salah satunya adalah penyandang disabilitas tunagrahita yang ada di komunitas Mondoroko Malang. Memberikan edukasi kepada mereka tentunya bukan pekerjaan mudah karena mengingat keterbatasan intelektual mereka. Para penyandang disabilitas tunagrahita yang ada di komunitas Mondoroko memang tidak bisa mengikuti pendidikan seperti anak normal pada umumnya, namun masih ada banyak cara untuk membawa mereka agar bisa sedikit memahami apa itu ekologis, oleh karena itu di komunitas Bhakti Luhur Mondoroko diadakan katekese umat tentang literasi ekologis kepada mereka . Mengapa katekese umat dipilih untuk memberikan materi literasi ekologis karena cara ini sering kali digunakan untuk memberikan semacam pembelajaran non formal mengingat usia mereka yang bukan anak-anak lagi.

\section{METODE PENELITIAN}

Dalam penelitian ini peneliti menggunakan pendekatan dan jenis penelitian kuantitatif. Penelitian kuantitatif adalah suatu proses menemukan pengetahuan yang menggunakan data berupa angka sebagai alat menganalisis keterangan mengenai apa yang ingin diketahui (Kasiram, 2008, 149) dalam bukunya Metodologi Penelitian Kualitatif dan Kuantitatif. Adapun lokasi penelitian ini adalah di komunitas penyandang disabilitas Bhakti Luhur Mondoroko Malang. 
Sumber data dalam penelitian ini yaitu sumber data primer. Data primer diperoleh dari penilaian pengasuh sebanyak 6 pengasuh. Mereka menilai para penyandang disabilitas tunagrahita yang mengikuti katekese umat tentang literasi ekologi. Instrumen yang dipakai oleh peneliti untuk memperoleh data ini dalam bentuk kuesioner. Kuesioner diberikan kepada 6 pengasuh berdasarkan data responden.

Populasi dalam penelitian ini berjumlah 42 orang yang terdiri dari berbagai macam penyandang disabilitas yang berada di komunitas Bhakti Luhur Mondoroko. Dari 42 orang yang ada peneliti mengambil 10 orang saja yang menyandang disabilitas tunagrahita dengan pertimbangan bahwa para penyandang tunagrahita yang secara fisik normal walau memiliki kecerdasan di bawah rata-rata. Pemilihan ini sengaja dilakukan karena mereka masih bisa menjalankan pemeliharaan lingkungan tentunya dengan bimbingan pengasuh. Sementara penyandang disabilitas yang lain adalah para penyandang cerebral palsy yang duduk di kursi roda dan penyandang tunalaras.

Adapun data responden adalah sebagai berikut:

\begin{tabular}{ccccll}
\hline No. & NN & L/P & Usia & \multicolumn{1}{c}{ Alamat } & \multicolumn{1}{c}{ Kasus } \\
\hline 1 & DU & P & 30 & Mondoroko lima & Tunagrahita Ringan Murni \\
\hline 2 & TW & P & 27 & Mondoroko lima & Tunagrahita Ringan Murni \\
\hline 3 & S & P & 25 & Mondoroko tiga & Tunagrahita Sedang Murni \\
\hline 4 & MY & P & 36 & Mondoroko empat & Tunagrahita Ringan Murni \\
\hline 5 & Y & P & 32 & Mondoroko tiga & Tunagrahita Ringan Murni \\
\hline 6 & NY & P & 36 & Mondoroko enam & Tunagrahita dengan down syndrome \\
\hline 7 & DW & P & 39 & Mondoroko enam & Tunagrahita dengan down syndrome \\
\hline 8 & EP & P & 50 & Mondoroko dua & Tunagrahita Sedang Murni \\
\hline 9 & Y & P & 40 & Mondoroko satu & Tunagrahita Sedang Murni \\
\hline 10 & FW & P & 42 & Mondoroko satu & Tunagrahita Ringan Murni \\
\hline
\end{tabular}

Untuk metode yang dipakai dalam pengumpulan data adalah metode kuesioner, sedangkan instrumennya ialah angket dan skala bertingkat. Jenis kuesionernya tertutup di mana peneliti sudah menyediakan jawaban sehingga responden tinggal memilih. Jika dipandang dari segi jawaban, maka kuesioner ini tergolong kuesioner tidak langsung di mana jawaban diperoleh dari pengasuh karena para penyandang tunagrahita tidak mampu menilai dirinya sendiri. Jika dipandang dari bentuknya, maka peneliti memakai bentuk rating-scale yaitu sebuah pernyataan diikuti oleh kolom-kolom yang menunjukkan dua alternatif jawaban yaitu ya dan tidak yang didasarkan pada skala Gutman (Sugiyono, 2019,234). Teknik analisa data menggunakan F persen.

\section{HASIL}

Penelitian ini memiliki satu variabel yaitu pelaksanaan katekese umat tentang literasi ekologis bagi penyandang tunagrahita. Berdasarkan hasil pengolahan angket/kuesioner yang telah diisi oleh responden yang diwakili oleh pengasuh terhadap 10 responden hasilnya adalah sebagai berikut: responden berinisial DU memperoleh nilai sebesar 86,6\%, TW sebesar 100\%, S sebesar $100 \%$, MY sebesar 93,3\%, N sebesar 93,3\%, Y sebesar 80\%, DW sebesar 93,3\%, E sebesar, 100\%, Y sebesar $100 \%$, FW sebesar $93,3 \%$. 


\section{PEMBAHASAN}

\section{Pengertian Katekese}

Kata katekese berasal dari kata catechein (kt. Kerja) dan catechein (kt. Benda). Akar katanya adalah kat dan echo. Kat artinya keluar, ke arah luas dan echo artinya gema/gaung. Berarti makna profan dari katekese adalah suatu gema yang diperdengarkan/disampaikan ke arah luas/keluar. Gema dapat terjadi jika ada suara yang penuh dengan keyakinan dan gema tidak pernah berhenti pada satu arah, maka katekese juga harus dilakukan dengan penuh keyakinan dan tidak pernah berhenti pada satu arah.

\section{Dasar Katekese}

Dasar katekese adalah "penugasan Kristus kepada para rasul dan pengganti-pengganti mereka". Dalam Mat 28 :19-20, Yesus mengutus para rasul untuk "pergi”, "menjadikan semua bangsa murid-Ku", "baptislah mereka dalam nama Bapa dan Anak dan Roh Kudus", dan "ajarlah mereka melakukan segala sesuatu yang telah Kuperintahkan kepadamu”.

Dalam tafsir Injil Matius dijelaskan bahwa tugas para rasul mencakup pewartaan awal kepada orang yang belum mengenal Tuhan, pengajaran kepada para katekumen, dan pengajaran kepada orang yang telah menjadi anggota Gereja agar iman mereka lebih mendalam

Subjek Katekese

Katekese adalah karya Gereja yang mendasar. Gereja dipanggil untuk melanjutkan tugas Yesus, Sang Guru, dan diutus menjadi pengajar iman, dengan dijiwai oleh Roh Kudus. Oleh karena itu subyek katekese adalah Gereja. Iman yang diajarkan oleh Gereja dalam iman yang dihidupi oleh Gereja itu sendiri, yaitu:
a) Pemahaman tentang Allah dan rencana penyelamatan-Nya
b) Pandangan tentang manusia adalah ciptaan yang paling mulia
c) Warta Kerajaan Allah
d) Harapan dan Kasih

\section{Objek Katekese}

Tujuan definitif katekese adalah bukan hanya membuat orang saling berkontak, melainkan juga dalam kesatuan dan kemesraan, dengan Yesus Kristus. Segala kegiatan mewartakan Kabar Gembira dimengerti sebagai usaha mempererat kesatuan dengan Yesus Kristus. Mulai dengan pertobatan 'awal' seseorang kepada Tuhan yang digerakkan oleh Roh Kudus melalui pewartaan Injil yang pertama, katekese berusaha mengukuhkan dan mematangkan kesetiaan pertama ini.

\section{Bentuk Katekese}

Ditinjau dari segi penyajiannya, katekese dapat dibedakan dalam 3 bentuk :

a) Bentuk Praktis

Bentuk ini mengarahkan peserta katekese untuk bergiat dan rajin dalam mempraktikkan kehidupan agamanya: rajin beribadah, rajin berdoa dan berdevosi, bergairah menghadiri perayaan Ekaristi dan perayaan lain, mengenal baik masa-masa liturgis segala sarana dan peralatannya. Sumber utamanya adalah liturgi Gereja.

b) Bentuk Historis

Bentuk ini memperdalam pengenalan umat akan sejarah penyelamatan dari pihak Allah, yang diawali dengan janji-janji mesianis dalam Perjanjian Lama dan memuncak dalam pribadi Kristus dalam Perjanjian Baru. Sumber utamanya adalah Kitab Suci. 
c) Bentuk Sistematis

Bentuk ini menyajikan kepada umat ajaran teologis dan dogmatis yang tersusun secara sistematis, singkat, dan padat. Sumbernya adalah buku Katekismus.

Pada praktiknya bentuk-bentuk tersebut berbaur. Tidak murni hanya satu bentuk yang dilaksanakan. Sebab nampaknya unsur-unsur yang ditekankan oleh masing-masing bentuk saling berkaitan. Ajaran biblis, historis, teologis, dogmatis dimaksudkan untuk membantu umat semakin menyadari penyelamatan Allah melalui Gereja-Nya. Dengan kesadaran itu umat diharapkan akan terdorong untuk semakin giat dalam praktik-praktik keagamaan.

\section{Prinsip - Prinsip Katekese}

a) Usaha katekese merupakan tanggung jawab seluruh umat sebagai Gereja

b) Usaha katekese mementingkan "proses" (bukan hasil yang langsung/"instan"). Dengan kata lain : yang lebih utama adalah bukan "target"/"hasil" yang sudah dicapai, melainkan "proses" menuju/memperoleh hasil.

c) Peserta katekese sebagai "subyek"/pelaku yang berperan dalam proses.

d) Katekese membantu orang menghayati imannya dalam situasi aktual (orang mampu mewujudkan imannya secara konkret dalam hidup/ada integritas antara iman dan hidup bersama orang lain).

e) Katekese berupaya mendorong umat untuk membangun relasi yang harmonis dengan Tuhan, sesama maupun lingkungannya. Dalam hal ini, proses katekese yang bertujuan mematangkan dan mendewasakan iman harus dilaksanakan secara sadar dan terencana dengan penuh tanggung jawab (tidak "improvisasi")

f) Katekese harus memperhitungkan situasi peserta (latar belakang, psikologi, minat, kebutuhannya). Katekese harus menjadi lebih kontekstual.

g) Proses katekese adalah proses pendidikan iman yang membebaskan. Dalam proses katekese setiap pribadi dihargai martabatnya sederajat, di mana setiap orang bebas mengungkapkan pengalaman imannya tanpa rasa takut. Dalam hal ini setiap pengalaman iman dari masing-masing pribadi harus dilihat sebagai pengalaman yang dapat memperkaya sesamanya dalam proses berkatekese.

h) Katekese diharapkan membangun iman yang "terlibat' (mendorong "aksi")

i) Pendamping katekese sebagai "fasilitator" yang memudahkan terjadinya komunikasi iman. Untuk itu, tidak tepatlah kalau pendamping bertindak sebagai orang yang 'maha tahu' apalagi sebagai penceramah yang mendominasi proses pertemuan.

j) Proses katekese harus mampu "menjemput/menyentuh" pengalaman hidup ataupun pengalaman iman peserta, sebagai medan pertemuan manusia dengan Allah.

k) Sarana maupun metode katekese yang diupayakan, semuanya bertujuan untuk memudahkan terjadinya komunikasi iman. pemikiran bahwa dalam pertemuan katekese "yang penting asal diisi dengan banyak kegiatan bagi umat" bertentangan dengan prinsip suatu proses katekese yang bertanggung jawab.

1) Katekese hanya salah satu dari upaya-upaya pastoral secara menyeluruh. Proses perkembangan iman harus dilengkapi dengan upaya-upaya pastoral yang lain.

Katekese sebagai pendidikan iman mempunyai tugas membangkitkan dan membina pengungkapan dan perwujudan iman umat dalam pelbagai macam bentuknya antara lain pendidikan dalam kehidupan doa dan sakramen, pendidikan dalam kehidupan moral, pendidikan 
dalam gerakan ekumenis, pendidikan dalam kepedulian akan masyarakat terutama dalam memperjuangkan perdamaian, keadilan, kebenaran dan lingkungan hidup (Adisusanto, 2000: 12). Kita tahu bahwa dengan berkatekese, kita mau supaya umat (anggota Gereja) semakin beriman. Iman itu paling kurang memiliki tiga dimensi, yaitu: pengetahuan tentang ajaran imannya (dimensi teologis), perwujudan imannya dalam hidup sehari-hari (dimensi moral) dan ungkapan imannya dalam ibadah (dimensi liturgis). Jadi kita berharap bahwa dengan katekese kita dapat membantu umat untuk lebih mengenal ajaran imannya, lalu dapat mewujudkan imannya dalam konteks hidup sehari-hari dan berpuncak pada ungkapan imannya dalam doa dan ibadah. Tiap-tiap dimensi iman itu dapat dibantu perwujudan dan perkembangannya oleh pola-pola katekese tertentu sesuai perannya, walaupun tidak dapat terlalu dipilah-pilah dan dikotak-kotakkan, sebab semuanya saling terkait dan menyatu satu sama lain.

\section{Katekese umat}

Katekese Umat (KU) diartikan sebagai komunikasi iman atau tukar pengalaman iman (penghayatan iman) antara anggota jemaat atau kelompok Melalui kesaksian para peserta saling membantu sedemikian rupa, sehingga iman masing-masing diteguhkan dan dihayati secara makin sempurna. Dalam katekese umat tekanan terutama diletakan pada penghayatan iman, meskipun pengetahuan tidak dilupakan.

Dalam Katekese Umat itu kita bersaksi tentang iman kita akan Yesus Kristus, pengantara Allah yang bersabda kepada kita dan pengantara kita menanggapi sabda Allah. Yesus Kristus tampil sebagai pola hidup kita dalam Perjanjian Baru, yang mendasari penghayatan iman Gereja sepanjang tradisinya. Katekese Umat merupakan komunikasi iman dari peserta sebagai sesama derajat, yang saling bersaksi tentang iman mereka. Peserta berdialog dalam suasana terbuka, ditandai sikap saling menghargai dan saling mendengarkan.(Yosef Lalu, 2007, 89).

\section{Literasi Ekologis}

Literasi ekologis juga disebut sebagai ekoliterasi adalah kemampuan untuk memahami sistem alam yang memungkinkan kehidupan di bumi. Menjadi ekoliterasi berarti memahami prinsip-prinsip organisasi komunitas ekologis yaitu ekosistem dan menggunakan prinsip-prinsip tersebut untuk menciptakan komunitas manusia yang berkelanjutan, dengan demikian sebuah nilai baru memasuki pendidikan kesejahteraan bumi.

Masyarakat yang melek ekologis akan menjadi masyarakat yang berkelanjutan yang tidak merusak lingkungan alam tempat mereka bergantung. Literasi ekologi adalah konsep yang kuat karena menciptakan landasan untuk pendekatan terpadu terhadap masalah lingkungan. Para advokat memperjuangkan eko-literasi sebagai paradigma pendidikan baru yang muncul di sekitar kutub holisme, pemikiran sistem, keberlanjutan, dan kompleksitas Ekoliterasi berkaitan dengan pemahaman prinsip-prinsip organisasi ekosistem dan penerapan potensinya untuk memahami bagaimana membangun masyarakat manusia yang berkelanjutan (Orr, 1990).

Ekoliterasi atau literasi ekologi adalah suatu aktivitas memahami pentingnya menjaga kelestarian lingkungan yang didukung dengan 15 sebuah cabang kekuatan pengetahuan lingkungan sadar lingkungan (Sarmiasih, 2018). Hal ini diperkuat menurut pendapat Capra (2013) menjelaskan ekoliterasi atau melek lingkungan merupakan kemampuan atas kesadaran tinggi tentang pentingnya lingkungan hidup dengan segala isinya yang memang harus di manfaatkan secara bijak. Kekuatan pengetahuan inilah sebagai senjata yang harus dibangun sejak dini salah satunya mengajak masyarakat untuk bisa membuka pola pikir (open mindset) dan mengaktualisasikan peran preventif dalam mengurangi masalah degradasi lingkungan. Efendi, 
(2015) dalam (Sarmiasih, 2018), menegaskan bahwa akibat permasalahan lingkunganlah yang menjadi input untuk menemukan cara cerdas keluar dalam lingkaran setan bencana ekologi.

Konsep literasi lingkungan atau literasi ekologi ditegaskan oleh Environment Education and Training Partnership (EETAP) yang menyatakan dengan luas bahwa seseorang yang melek lingkungan dia tahu yang akan dia lakukan untuk lingkungan, dia tahu bagaimana cara melakukan hal tersebut NAAEE, 2011 (Nasution, 2016). Status literasi lingkungan seseorang dapat diukur berdasarkan kriteria komponen-komponen literasi lingkungan. Adapun kriteria literasi lingkungan sebagai berikut: 1) Pengetahuan Ekologi/ Lingkungan Pengetahuan Ekologi/ Lingkungan adalah IPTEK yang mempelajari tentang proteksi lingkungan dari penyebab potensial aktivitas manusia, proteksi masyarakat dari pengaruh yang merugikan, dan peningkatan kualitas lingkungan untuk kesehatan serta kehidupan yang layak bagi manusia. Pengetahuan ekologi yang dimaksud dalam penelitian ini yaitu untuk mengetahui pemahaman para penyandang disabilitas mengenai pelestarian lingkungan di mana mereka tinggal.

\section{Tunagrahita}

Pertama, Definisi tunagrahita

Kata tunagrahita berasal dari kata tuna yang artinya kerusakan atau gangguan dan grahita berarti pikiran (Heri Zan Pieter, 2017, 256). Dengan demikian, tunagrahita adalah gangguan atau kelemahan dalam berpikir. Kurangnya kemampuan ini mengakibatkan kemampuan belajar mereka berada di bawah rata-rata. Tunagrahita atau terbelakang mental merupakan kondisi di mana perkembangan kecerdasannya mengalami hambatan sehingga tidak mencapai tahap perkembangan yang optimal. Anak tunagrahita memiliki kapasitas intelektual (IQ) di bawah 70 yang disertai dalam penyesuaian diri dengan lingkungan, sehingga memiliki berbagai masalah sosial (Sutjihati, 2012:103).

\section{Kedua, Penyebab tunagrahita}

a) Infeksi otak yang terjadi setelah bayi lahir.

b) Bayi lahir prematur.

c) Cedera pada otak karena kecelakaan atau jatuh.

d) Adanya kelainan pada gen yang diturunkan dari orang tua.

e) Bayi tidak mendapatkan cukup oksigen selama proses persalinan.

f) Ibu terkena infeksi ketika hamil.

g) Ibu mengonsumsi minuman keras, obat-obatan terlarang atau obat-obatan tertentu saat hamil.

\section{Ketiga, ciri-ciri tunagrahita}

James D. Page (1995) menyebutkan beberapa ciri-ciri yang dimiliki oleh penyandang Tunagrahita, yaitu kecerdasan intelektual, sosial, fungsi mental, dorongan dan emosi, kemampuan berbahasa, kemampuan secara akademis, dan kemampuan berorganisasi. Berikut penjelasannya:

a) Intelektual

Tingkat kecerdasan penyandang Tunagrahita selalu di bawah rata-rata teman sebayanya. Perkembangan kecerdasannya juga sangat terbatas. Umumnya, mereka hanya mampu mencapai tingkat usia mental setingkat anak SD kelas IV atau bahkan ada yang hanya mampu mencapai tingkat usia mental anak pra-sekolah.

b) Sosial 
Kemampuan bidang sosial anak Tunagrahita mengalami keterlambatan. Hal ini ditunjukkan dengan kemampuan anak Tunagrahita yang rendah dalam hal mengurus, memelihara, dan memimpin dirinya sendiri sehingga acap kali tidak mampu bersosialisasi dengan orang lain.

c) Fungsi Mental

Anak Tunagrahita mengalami kesukaran dalam memusatkan perhatian, jangkauan perhatiannya sangat sempit dan cepat beralih sehingga kurang mampu menghadapi tugas.

d) Dorongan dan Emosi.

Perkembangan dorongan emosi anak Tunagrahita berbeda-beda tergantung pada tingkat klasifikasi Tunagrahita yang dimiliki. Pada tingkat Severe dan Profound, penyandang Tunagrahita umumnya tidak dapat menunjukkan dorongan untuk mempertahankan diri. Contoh, mereka tidak dapat memberi tahu saat sedang merasa lapar, tidak dapat menjauhkan diri saat mendapat stimulus yang memberikan rasa sakit. Secara umum, kehidupan emosinya terbatas pada perasaan senang, takut, marah, dan benci.

e) Kemampuan dalam Bahasa

Kemampuan bahasa anak Tunagrahita sangat terbatas, terutama pada perbendaharaan kata. Anak Tunagrahita tingkat Severe dan Profound umumnya memiliki gangguan bicara berat yang disebabkan cacat artikulasi dan masalah dalam pembentukan bunyi di pita suara dan rongga mulut.

f) Kemampuan dalam Bidang Akademis

Anak Tunagrahita sulit mempelajari sesuatu yang bersifat akademis, terutama membaca dan berhitung. Namun, hal ini dapat diatasi dengan melakukan pendampingan belajar yang mendasar dan intensif.

g) Kepribadian dan Kemampuan Organisasi.

Dari berbagai penelitian oleh Leahy, Balla, dan Zigler (dalam Hallahan, 1988), disebutkan bahwa anak Tunagrahita umumnya memiliki kepercayaan diri yang rendah sebab tidak mampu mengontrol dirinya sendiri dan bergantung pada orang lain. Hal tersebut berdampak pada kemampuan berorganisasi yang sangat kurang.

\section{Keempat, Klasifikasi Anak Tunagrahita}

Klasifikasi menurut AAMD (Moh. Amin, 1995: 22-24), sebagai berikut:

a) Tunagrahita Ringan (Mampu Didik)

Tingkat kecerdasannya IQ mereka berkisar 50 - 70 mempunyai kemampuan untuk berkembang dalam bidang pelajaran akademik, penyesuaian sosial dan kemampuan bekerja, mampu menyesuaikan lingkungan yang lebih luas, dapat mandiri dalam masyarakat, mampu melakukan pekerjaan semi terampil dan pekerjaan sederhana.

b) Tunagrahita Sedang (Mampu Latih)

Tingkat kecerdasan IQ berkisar 30-50 dapat belajar keterampilan sekolah untuk tujuan fungsional, mampu melakukan keterampilan mengurus dirinya sendiri (self-help), mampu mengadakan adaptasi sosial dilingkungan terdekat, mampu mengerjakan pekerjaan rutin yang perlu pengawasan.

c) Tunagrahita Berat dan Sangat Berat (Mampu Rawat)

Tingkat kecerdasan IQ mereka kurang dari 30 hampir tidak memiliki kemampuan untuk dilatih mengurus diri sendiri. Ada yang masih mampu dilatih mengurus diri sendiri, berkomunikasi secara sederhana dan dapat menyesuaikan diri dengan lingkungan sangat terbatas. 
Sedangkan klasifikasi yang digunakan di Indonesia saat ini (PP No. 72/1999) adalah:

1) Tunagrahita ringan IQ-nya $50-70$.

2) Tunagrahita sedang IQ-nya $30-50$.

3) Tunagrahita berat dan sangat berat IQ-nya kurang dari 30.

Bertitik tolak dari hasil penelitian di atas, peneliti membuat beberapa saran demi pengembangan dan peningkatan aksi nyata dari para penyandang disabilitas tunagrahita yang ada di wisma Bhakti Luhur Mondoroko.

a) Perlu adanya monitoring dan evaluasi terhadap aksi nyata yang dilakukan oleh para penyandang disabilitas mengingat daya pikir mereka yang rendah sehingga membuat mereka lupa untuk terus menjaga lingkungan di mana mereka tinggal.

b) Dibuatkan jadwal bagi mereka untuk terlibat dalam menjaga ekologi di lingkungan mereka tinggal agar mereka sadar bahwa mereka juga bagian dari pihak yang ikut bertanggungjawab dalam memelihara lingkungan yang bersih dan sehat

c) Memberi tanggung jawab kepada mereka untuk mengelola hasil katekese umat sebagai wujud aksi nyata

\section{KESIMPULAN}

Penelitian mengenai survei hasil pelaksanaan katekese umat tentang literasi ekologis bagi penyandang disabilitas tunagrahita di lingkungan Santo Filemon Mondoroko Malang dilatarbelakangi oleh minimnya pemahaman para penyandang disabilitas tunagrahita untuk ikut ambil bagian dalam pemeliharaan lingkungan hidup. Sebagai contoh mereka tidak tahu bagaimana harus membuang sampah pada tempatnya, merawat tanaman yang ada di kebun, menyapu halaman dan kebun, hanya duduk-duduk sepanjang hari dan sulit terlibat dalam kegiatan berkebun sehingga membuat mereka terkesan cuek dan malas.

Dari hasil penelitian survei aksi nyata pelaksanaan katekese umat tentang literasi ekologi bagi para penyandang disabilitas tunagrahita ternyata hasilnya cukup signifikan yaitu dari 10 penyandang tunagrahita yang dipantau diperoleh hasil 93,9\%. Ini menunjukkan bahwa mereka sangat antusias untuk ikut ambil bagian dalam pemeliharaan lingkungan. Tetapi perlu juga diingat bahwa karena mereka penyandang disabilitas maka aksi nyata mereka perlu terus dipantau. 


\section{DAFTAR PUSTAKA}

Adisusanto, FX. (1991). Kateketik Umum. Yogyakarta: STFK

Amin, Muhamad. (1995). Orthopedagogik Anak Tunagrahita. Bandung. Depdikbud.

Capra, Fritjof. (1997). Titik Balik Peradaban: Sains, Masyarakat dan Kebangkitan Kebudayaan. Alih Bahasa: M.Thoyibi. Yogyakarta: Bentang Budaya.

Hallahan, D.P. \& Kauffman, J.M. (2006). Exceptional Learners: Introduction to Special Education 10th ed. USA: Pearson.

http://www.imankatolik.or.id/

Kasiram, Moh. (2008). Metodologi Penelitian. Malang: UIN-Malang Pers

Keraf , A.Sonny. (2010). Etika Lingkungan Hidup. Jakarta: Buku Kompas

Lalu, Yosef. (2007). Katekese Umat. Jakarta: Komisi Kateketik KWI

McBeth, B., H. Hungerford, T. Marcinkowski, T. Volk, and R. Meyers. (2008). National Environmental Literacy Assessment Project: year 1, national baseline study of middle grades students-final research report. Environmental Protection Agency, Washington, D.C., USA.

Peraturan Pemerintah No 72/1999 tentang Klasifikasi Tunagrahita

Pieter, Heri Zan. (2017). Dasar-Dasar Komunikasi Bagi Perawat. Jakarta: PT. Kharisma Putra Utama,

Hallfreðsdóttir, Salome. (2011). Eco Schools - Are They Really Better?. Thesis: Lund University. Dalam http:// www.eco-schools.org/brochure_eco

Sarmiasih, Mia. (2018). "Gerakan Literasi Ekologi (Ekoliterasi) Kritis Sebagai Respon Terhadap Isu Pemanasan Global”. Jurnal. Yogyakarta: Universitas Muhammadiyah Yogyakarta.

Sugiyono. (2018). Metode Penelitian Kuantitatif, Kualitatif dan R\&D. Bandung: Alfabeta. Somantri, Sutjihati. (2012). Psikologi Anak Luar Biasa. Bandung: PT Refika Aditama. Tanzeh, Ahmad. (2011). Metodologi Penelitian Praktis. Yogyakarta: Teras. 